\title{
Erratum to: How Can Psychological Science Inform Research About Genetic Counseling for Clinical Genomic Sequencing?
}

\author{
Cynthia M. Khan - Christine Rini - Barbara A. Bernhardt • J. Scott Roberts • \\ Kurt D. Christensen • James P. Evans • Kyle B. Brothers • Myra I. Roche • \\ Jonathan S. Berg • Gail E. Henderson
}

Published online: 25 December 2014

(C) National Society of Genetic Counselors, Inc. 2014

\section{Erratum to: J Genet Counsel \\ DOI 10.1007/s10897-014-9804-6}

Grant support from the Clinical Sequencing Exploratory Research program of the National Human Genome Research Institute was awarded to James P. Evans, Jonathan S. Berg, and Gail E. Henderson for the NCGENES Study (NIH \#U01 HG006487). The authors and publisher regret the omission from the original article.

The online version of the original article can be found at http://dx.doi.org/ 10.1007/s10897-014-9804-6.

\section{M. Khan $(\triangle)$}

Department of Health Behavior, University of North

Carolina-Chapel Hill, 312 Rosenau Hall, CB\#7440, Chapel Hill,

NC 27599-7440, USA

e-mail: ckhan@med.unc.edu

C. Rini

Health Behavior, Lineberger Comprehensive Cancer Center,

University of North Carolina-Chapel Hill, Chapel Hill, NC, USA

B. A. Bernhardt

Translational Medicine and Human Genetics, University of

Pennsylvania, Philadelphia, PA, USA

\section{J. S. Roberts}

Health Behavior\&Health Education, Center for Bioethics and Social

Sciences in Medicine, University of Michigan-Ann Arbor, Ann

Arbor, MI, USA

\section{K. D. Christensen}

Genetics, Department of Medicine, Brigham and Women's Hospital and Harvard Medical School, Boston, MA, USA

J. P. Evans $\cdot$ M. I. Roche $\cdot$ J. S. Berg

Genetics, University ofNorth Carolina-Chapel Hill, Chapel Hill, NC, USA

K. B. Brothers

Family and Geriatric Medicine, University of Louisville School of Medicine, Louisville, KY, USA

M. I. Roche

Pediatrics, University of North Carolina-Chapel Hill, Chapel Hill, NC, USA

G. E. Henderson

Social Medicine, Center for Genomics \& Society, University of North Carolina-Chapel Hill, Chapel Hill, NC, USA 